\title{
Limited cutaneous systemic sclerosis
}

INSERM

\section{Source}

INSERM. (1999). Orphanet: an online rare disease and orphan drug data base. Limited cutaneous systemic sclerosis. ORPHA:220402

Limited cutaneous systemic sclerosis (IcSSc) is a subtype of systemic sclerosis (SSc; see this term) characterized by the association of Raynaud's phenomenon with skin fibrosis limited to the hands, face, feet and forearms. 